\title{
PREVALÊNCIA DE UNIVERSITÁRIOS QUE FAZEM USO DE MEDICAMENTOS PARA TRATAMENTO DE DISFUNÇÃO ERÉTIL
}

\section{PREVALENCE OF UNIVERSITIES THAT MAKE USE OF MEDICINES FOR ERECTILE DYSFUNCTION TREATMENT}

\author{
Mayara HORNUNG ${ }^{1}$; Gerusa Clazer HALILA²; Vanessa BARBOSA ${ }^{3}$ \\ ${ }^{1}$ Farmacêutica \\ email: mayara_hornung@yahoo.com.br \\ ${ }^{2}$ Docente do Curso de Farmácia do Centro de Ensino Superior dos Campos Gerais \\ - CESCAGE \\ email: gerusach@hotmail.com \\ ${ }^{3}$ Acadêmica do Curso de Farmácia do Centro de Ensino Superior dos Campos \\ Gerais - CESCAGE \\ email: vanessabarbosa273@bol.com.br
}

\begin{abstract}
RESUMO:
O objetivo deste trabalho foi verificar a prevalência de universitários que fazem uso de medicamentos para tratamento de disfunção erétil em uma instituição privada de ensino superior, na cidade de Ponta Grossa - PR, em 2010. Participaram da pesquisa 429 acadêmicos do sexo masculino, com idade entre 18 e 30 anos, os quais responderam um questionário sobre o conhecimento dos medicamentos para disfunção erétil, diagnóstico da patologia, frequência e motivo do uso, o medicamento utilizado, onde foi adquirido, se teve prescrição médica e o relato de reações adversas. Os resultados mostraram que $8,6 \%$ dos acadêmicos fizeram uso de medicamentos para disfunção erétil, sendo que destes, 5\% relataram usar pelo menos uma vez por mês. Dentre os acadêmicos que relataram uso, $31 \%$ disseram usar Viagra ${ }^{\circledR}$ (sildenafila), 20\% Pramil $^{\circledR}$ (sildenafila) e $20 \%$ Cialis $^{\circledR}$ (tadalafila), sendo que apenas dois acadêmicos adquiriram a partir de receituário médico, mesmo não apresentando nenhum problema de disfunção erétil. Quanto ao local onde foram adquiridos os medicamentos, $40 \%$ disseram ter conseguido na farmácia, 19\% com amigos e $14 \%$ no Paraguai. Dos acadêmicos que já fizeram uso, $62 \%$ não relataram nenhuma reação adversa e dos $38 \%$ que relataram reações, $37 \%$ disseram ter dor de cabeça e $22 \%$ rubor facial, sendo citados também ereção prolongada do pênis e suor excessivo, reações menos comuns. Os principais motivos que levaram ao uso destes medicamentos foram curiosidade (87\%) e melhor desempenho (8\%).
\end{abstract}

Palavras-chave: disfunção erétil; medicamentos; acadêmicos.

\section{ABSTRACT:}

The aim of this study was to assess the prevalence of students who use drugs to treat erectile dysfunction in a private institution of higher education in the city of Ponta Grossa - PR, in 2010. 429 students participated in the survey were male, aged between 18 and 30 years, who answered a questionnaire on knowledge of medications for erectile dysfunction, diagnosis of disease, frequency and reasons for using the medication used, where it was purchased, if had a prescription and reporting of adverse reactions. 
The results showed that $8.6 \%$ of the students made use of medications for erectile dysfunction, and of these, $5 \%$ reported using at least once a month. Among academics who reported use, $31 \%$ said they used Viagra ${ }^{\circledR}$ (sildenafil), 20\% Pramil $^{\circledR}$ (sildenafil) and $20 \%$ Cialis $^{\circledR}$ (tadalafil), and only bought from two academic medical prescription, while not presenting any problems erectile dysfunction. As to where the drugs were purchased, $40 \%$ said they had achieved in the pharmacy, $19 \%$ with friends and $14 \%$ in Paraguay. Among academics who have already used, $62 \%$ reported no adverse reaction and the $38 \%$ who reported reactions, $37 \%$ said they had headaches and $22 \%$ facial flushing, and also cited prolonged erection of the penis and excessive sweating, less common reactions. The main reasons that led to the use of these drugs were curiosity (87\%) and better performance (8\%).

Key words: erectile dysfunction; medicinal products; undergraduates.

\section{INTRODUÇÃO}

A disfunção erétil, conhecida também como impotência sexual masculina, se caracteriza como a dificuldade de obter ou manter a ereção do pênis o tempo suficiente para permitir um desempenho sexual satisfatório (DELATE; SIMMONS; MONTHERAL, 2004).

Neste sentido, a disfunção erétil é um fenômeno que envolve diversos fatores e sistemas, como o endócrino, o nervoso, o vascular e tecidual dos corpos cavernosos. $O$ desequilíbrio de qualquer um destes fatores, pode resultar na perda da capacidade de ereção peniana (SBU, 1998).

Para o tratamento da disfunção erétil, primeiramente deve ser realizada uma avaliação clínica para investigação das causas subjacentes da disfunção e, com isto, escolher qual o tratamento mais indicado para cada paciente (FREITAS et al., 2008).

Atualmente, não são necessários exames complexos para fazer o diagnóstico. A prioridade básica da disfunção erétil é a dosagem da testosterona (hormônio masculino), da glicose (exame do diabetes) e do colesterol (OLD, 2000).

Estudos afirmam que a disfunção erétil acomete $45,1 \%$ de homens brasileiros, em algum grau. No entanto, com o avanço da idade a disfunção erétil acomete um número maior de homens e consequentemente manifesta agravamento em sua patologia. Entre 18 e 39 anos, 32\% dos brasileiros têm disfunção erétil mínima; 10,3\% têm disfunção erétil moderada e 1,1\% têm disfunção erétil completa (impotência). 
Acima dos 70 anos há $21,1 \%$ de disfunção erétil mínima, 35,1\% de disfunção erétil moderada e 12,3\% de disfunção erétil completa (CASTILHO et al., 2006).

Os tratamentos para a disfunção erétil são tão variados quanto as suas causas. Os métodos que podem ser utilizados para o tratamento da disfunção erétil são a psicoterapia, as próteses penianas, as cirurgias e os medicamentos, administrados por via oral ou injetável, em que as injeções são aplicadas diretamente no pênis (SOUSA, 2008; OLD, 2000).

Dentre todos os tipos de tratamento, no Brasil o uso de medicamentos inibidores de fosfodiesterase-5 (PDE-5) é o que apresenta maior aceitação e eficácia terapêutica. São comercializados no Brasil o sildenafil, vardenafil e tadalafil (DELATE; SIMMONS; MONTHERAL, 2004).

Existe boa tolerância desta classe de fármacos pela maioria dos pacientes que faz uso, apresentando efeitos adversos menos graves, como cefaléia, congestão nasal, dispepsia e visão anormal de cores. Efeitos adversos mais graves podem ocorrer em indivíduos que apresentem alterações cardiovasculares, ou com o uso concomitante de nitratos (FREITAS et al., 2008; SMITH; ROMANELLI, 2010).

O objetivo deste estudo foi identificar a utilização de medicamentos indicados para o tratamento da disfunção erétil por jovens universitários.

\section{MATERIAL E MÉTODOS}

Responderam ao questionário, acadêmicos com idade entre 18 e 30 anos, resultando num total de 429 acadêmicos de uma instituição privada de ensino superior na cidade de Ponta Grossa, Paraná. Esta instituição tem como total 2186 acadêmicos, sendo 904 do sexo masculino. A pesquisa foi realizada a partir da aprovação no Comitê de Ética em Pesquisa, nos meses de agosto e setembro de 2010. Este estudo é caracterizado como exploratório e descritivo.

Os acadêmicos que aceitaram participar como voluntários da pesquisa preencheram um questionário anônimo, composto por perguntas fechadas e abertas, sendo 10 perguntas sobre dados pessoais (como sexo, idade, estado civil), cinco perguntas sobre a vida sexual (por exemplo, idade da primeira relação, número de parceiras) e dez questões sobre o uso de medicamentos. As perguntas abordaram a presença ou não de diagnóstico médico de disfunção erétil, o conhecimento da 
existência desses medicamentos, a frequência e motivo do uso destes fármacos, o medicamento utilizado, a existência de prescrição médica e o relato de efeitos adversos da sua utilização.

Todos os participantes assinaram termo de consentimento livre esclarecido.

\section{RESULTADOS E DISCUSSÃO}

Dos 429 questionários respondidos pelos acadêmicos com idade entre 18 e 30 anos, 37 acadêmicos, ou seja, 8,6\% fizeram uso de medicamentos para problemas de disfunção erétil.

Neste estudo, os acadêmicos com 24 anos de idade foram os que mais fizeram uso desses medicamentos. Da mesma forma, os alunos com 21 anos relataram grande uso.

Quanto à frequência de uso dos medicamentos questionados, dos 37 acadêmicos que responderam ao questionário, 33 (90\%) relataram ter feito uso apenas uma vez, 2 (5\%) relataram usar pelo mês uma vez ao mês e 2 (5\%) não responderam. Sobre o motivo do uso, $87 \%$ dos acadêmicos relataram usar apenas por curiosidade, $8 \%$ para melhorar o desempenho sexual e 5\% não responderam.

Quanto ao local onde foram adquiridos esses medicamentos, 40\% dos acadêmicos disseram ter conseguido em farmácias, 14\% no Paraguai, 19\% com amigos e $27 \%$ em outros lugares. Dentre os medicamentos que mais foram citados como utilizados, $31 \%$ correspondem ao Viagra ${ }^{\circledR}$ e $19 \%$ ao Pramil $^{\circledR}$, tendo as duas especialidades farmacêuticas o princípio ativo sildenafil. $20 \%$ dos acadêmicos relataram ter utilizado Levitra $^{\circledR}$ (vardenafil), $5 \%$ usaram Cialis ${ }^{\circledR}$ (tadalafil) e os outros $25 \%$ relataram utilizar outros medicamentos ou não responderam. Apenas 2 universitários (5\%) afirmaram adquirir o medicamento com receituário médico. Porém, mesmo esses 2 acadêmicos que relataram adquirir o medicamento com receituário médico, nenhum mencionou ter problemas de disfunção erétil.

Dos acadêmicos que fizeram uso desses medicamentos, $62 \%$ não relataram nenhum tipo de reação adversa. Porém, dos 38\% que relataram reações, as principais foram dor de cabeça (37\%) e rubor facial $(22 \%)$. Também foram relatadas reações como suor excessivo (7\%), batimentos cardíacos acelerados (11\%), ereção prolongada do pênis (6\%) e pressão alta (4\%). Alguns acadêmicos não especificaram quais foram as reações observadas.

Percebe-se que o número de jovens que faz uso desse tipo de medicamento é alto em relação à faixa etária, pois os mesmos relataram não ter problemas de disfunção erétil ou em ter/manter a ereção.

Um dado preocupante foi o fato dos medicamentos serem utilizados de forma irresponsável, motivados apenas por curiosidade, reforçando o princípio da 
automedicação.

No estudo realizado por Freitas et al. (2008), 70\% dos acadêmicos também relataram ter feito uso apenas por curiosidade. Neste mesmo trabalho, os acadêmicos também relataram usar o medicamento para potencializar a ereção (12\%), contra ejaculação precoce (12\%) e para aumento do prazer (6\%). De acordo com Santtila et al. (2007), 16,4\% dos jovens relataram o uso desses medicamentos para aliviar o medo de ter algum tipo de problema durante a relação sexual, ou seja, fizeram uso para não ter insegurança. Nesse mesmo estudo, fez-se uma comparação entre homens com problemas de disfunção erétil e homens sadios, com relação ao melhor desempenho sexual durante a relação. Os resultados demonstram que os homens sadios, ao fazerem uso dos medicamentos para disfunção erétil, tiveram menor desempenho sexual em relação aqueles que possuíam problemas de disfunção erétil e faziam uso de medicamentos. Desta maneira, foi possível perceber que o uso desses medicamentos por jovens não é indicado, uma vez que não há comprovação de melhora no desempenho sexual.

No estudo de Freitas et al. (2008), as reações que mais foram relatadas também foram cefaléia (23\%) e rubor facial (10\%), ou seja as reações adversas citadas no estudo estão de acordo com a literatura.

O Viagra $^{\circledR}$ (sildenafil) foi o medicamento mais utilizado, provavelmente por ser o primeiro fármaco descoberto para esse fim, e ainda, devido ao grande número de propagandas sobre esse medicamento.

\section{CONCLUSÃO}

Os medicamentos usados para disfunção erétil não necessitam de controle especial ou retenção da prescrição médica no ato da dispensação, o que acaba se tornando um problema de saúde pública entre os jovens, que mesmo sem qualquer problema de disfunção, fazem seu consumo indiscriminadamente.

Diante dos resultados obtidos, deve-se ressaltar a importância do profissional farmacêutico perante o uso desses medicamentos, para que seja evitada a automedicação e o uso indiscriminado, levando em consideração o fato de os jovens adquirirem os medicamentos sem receita médica.

Apesar da larga comercialização dessa nova categoria de medicamentos, ainda são escassos os estudos que se propõem a verificar seu impacto na vida sexual e na saúde dos usuários. 


\section{REFERÊNCIAS}

CASTILHO, L. N.; FERREIRA, U.; NARDI, A. G.; VALIM, A. C. Disfunção erétil na terceira idade. Revista Brasileira Médica, v. 63, n. 7, p. 298-301, 2006.

DELATE, T.; SIMMONS, V. A.; MONTHERAL, B. R. Patterns of use of sildenafil among commercially insured adults in the United States: 1998-2002. Disponível em: <http://www.ncbi.nlm.nih.gov/pubmed/14973524>. Acesso em: 02 out. 2010.

FEITAS, V. M. de; MENEZES, F. G. de; ANTONIALLI, M. M. S.;NASCIMENTO, J. W. L. Frequência de uso de inibidores de fosfodiesterase-5 por estudantes universitários. Saúde Pública, São Paulo, v. 5, n. 42, p.965-967, 2008.

MUSACCHIO, N. S.; HARTRICH, M.; GAROFALO, R. Erectile dysfunction and vigra use: what. Journal of Adolescent Health, Chicago, v. 3, n. 2, p.452-454, 2006.

SANTTILA, P.; SANDNABBA, N, K.; JERN, P.; VARJONEN, M.; WITTING, K.; PAHLEN, B. von der. Recreational Use of Erectile Dysfunction Medication May Decrease Confidence in Ability to Gain and Hold Erections in Young Males. Disponível em: <http://www.medscape.com/viewarticle/565813>. Acesso em: 20 nov. 2010.

SMITH, K. M.; ROMANELLI, F. Recreational use and misuse of phosphodiesterase 5 inhibitors. Disponível em: <http://www.ncbi.nlm.nih.gov/pubmed/15730119>. Acesso em: 02 out. 2010.

SOUSA, J. L. Sexualidade na terceira idade: uma discussão da AIDS, envelhecimento e medicamentos para disfunção erétil. DST - Jornal Brasileiro de Doenças Sexualmente Transmissíveis, Recife - PB, v. 1, n. 20, p.59-64, 2008.

SOCIEDADE BRASILEIRA DE UROLOGIA. I Consenso brasileiro de disfunção erétil. São Paulo: BG Cultural, 1998.

OLD, B. Afinal, o que é disfunção erétil? Verdades e mentiras sobre a impotência sexual. Rio de Janeiro: Dunya, 2000. 